\title{
JAWS: THE IMPORTANCE OF SHARK FOSSILS FOR PALAEONTOLOGY RESEARCH
}

MOST OF OUR KNOWLEDGE OF PREHISTORIC SHARKS COMES FROM THEIR FOSSILISED TEETH. COMPLETE SHARK FOSSILS CAN TEACH US A HUGE AMOUNT ABOUT THE EXTRAORDINARY LIVES OF THESE EXTINCT ANIMALS, BUT PALAEONTOLOGISTS CAN STILL LEARN A LOT FROM JUST THEIR TEETH. PROFESSOR KENSHU SHIMADA, A SHARK PALAEONTOLOGIST AT DEPAUL UNIVERSITY IN CHICAGO, USA, HAS BEEN UNCOVERING THE MYSTERIES OF THE ICONIC MEGALODON AND MANY OTHER EXTINCT SHARKS

\section{TALK LIKE A \\ PALAEONTOLOGIST}

\section{COMPUTER TOMOGRAPHY (CT)}

- an imaging technique where multiple

$\mathrm{X}$-rays are taken of an object, then

compiled to produce a 3D image of the object's interior

ECOSYSTEM - all the organisms in an area, along with the non-living components

FOSSIL - the remains or traces of a prehistoric organism preserved in rock

OOPHAGY - an egg-eating behaviour exhibited by some animals

\section{VERTEBRAE - the series of}

segmented skeletal supports running through the body axis and containing the spinal cord

\section{VERTEBRATE - an animal that has} vertebrae (e.g., fish, amphibians, reptiles and mammals)
It is no wonder that the legendary megalodon has captured our imaginations. Three times longer than a great white shark, this ferocious creature once terrorised the oceans. But today, all that remains of these ancient hunters are their teeth, preserved in stone for millions of years, and questions about their existence. Just how large could they grow? How big were their babies? How long did they live? And what role did they play in prehistoric ecosystems?

By studying fossils of ancient sharks and comparing these to their modern-day relatives, Professor Kenshu Shimada, a shark palaeontologist at DePaul University, is hoping to solve some of the mysteries surrounding megalodon and other extinct sharks.

\section{LAMNIFORM SHARKS}

Professor Shimada's research focuses on a diverse group of sharks called lamniforms. Lamniform sharks include plankton-eaters such as the basking shark, as well as meateaters like the famous great white shark. "Although only 15 lamniform species live in today's ocean, there are many extinct species in the fossil record, including the iconic megatooth shark, Otodus megalodon," Professor Shimada explains.
"There is much more to learn about the biology of each species," he says. "We still don't know about the shape, growth and behaviour of many species, or the roles they played in their ecosystems." The discovery of new fossils, as well as the development of new methods to extract information from these fossils, will help palaeontologists like Professor Shimada to broaden our knowledge of prehistoric sharks.

WHAT CAN SHARK TEETH TELL US? Sharks are cartilaginous fish, with skeletons made from cartilage rather than bone. Only their teeth are well mineralised, made of calcium phosphate. This means when a shark dies and sinks to the ocean floor, its soft skeleton tends to decay quickly, leaving behind only its hard teeth.

"For this reason, most extinct sharks in the fossil record are represented by isolated teeth," explains Professor Shimada. "Teeth are usually the only clues left for palaeontologists to decipher ancient shark biology." While it is challenging to determine the structure and lifestyle of an entire species based solely on a few dental remains, these teeth do provide a huge amount of evidence about the life of prehistoric sharks. 


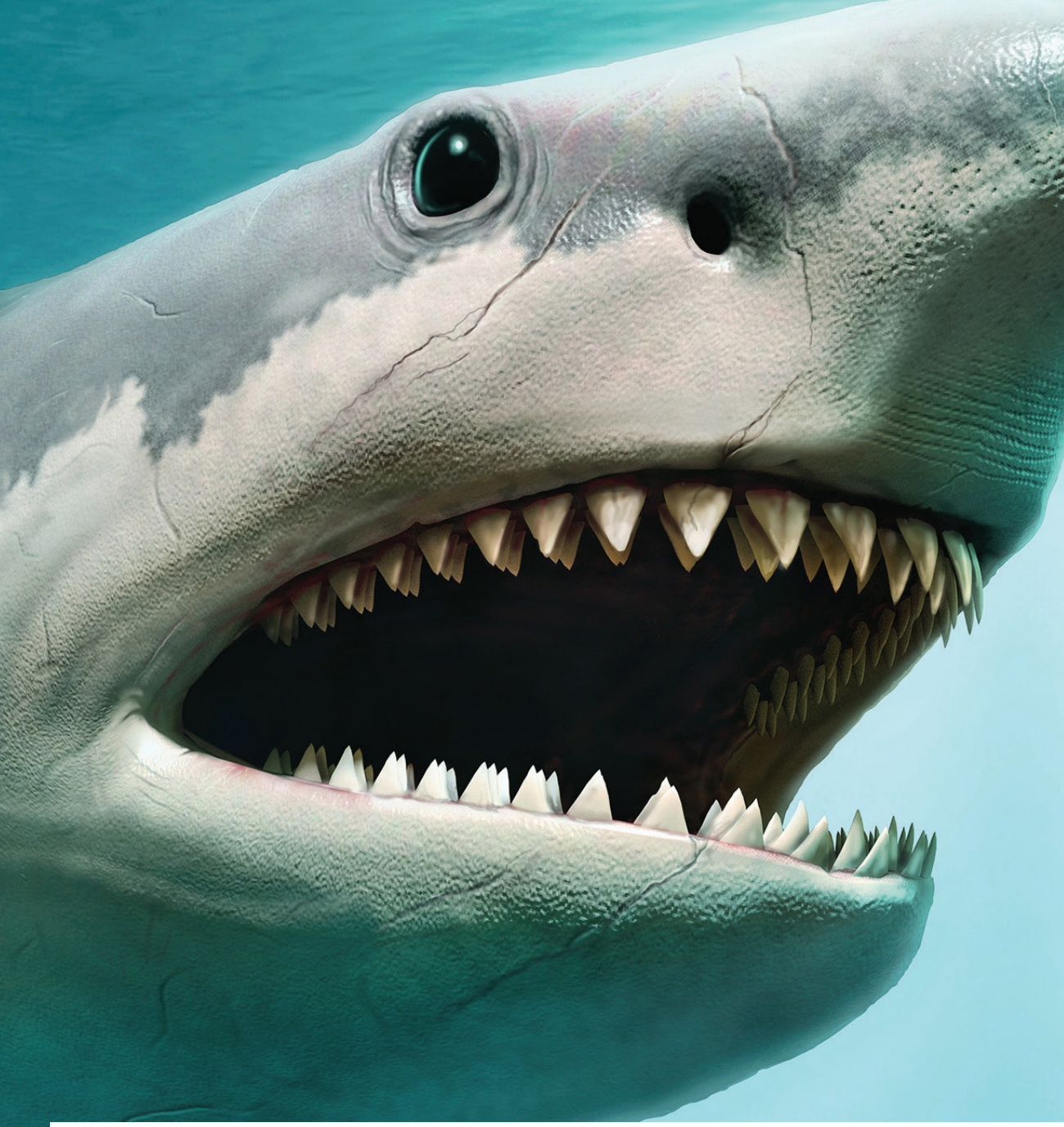

The shape of teeth provides clues as to what the shark ate. For example, flat teeth belonged to sharks which crushed shellfish, sharks which ate small fish and squid had pointy needle-like teeth, and sharp triangular teeth belonged to sharks which hunted large prey.

Palaeontologists can examine the chemical elements within fossils. Professor Shimada works with geochemists to determine chemical components preserved in fossilised shark teeth, which can indicate the likely diet and body temperature of extinct shark species, as well as ancient oceanic conditions in which the shark lived.

And the size of the teeth gives an indication of the size of the shark. Professor Shimada has examined the relationship between tooth size and body length in modern sharks. $\mathrm{He}$ uses this information to calculate the size of extinct sharks based on the size of their fossilised teeth. "Besides studying prehistoric sharks, I also study their modern relatives," he says. "Without understanding the anatomy of modern sharks, it is practically impossible to figure out the biology of extinct forms."

\section{WHAT HAS PROFESSOR SHIMADA} DISCOVERED ABOUT MEGALODON?

Recently, Professor Shimada studied an exceptionally well-preserved specimen of a megalodon that was discovered in Belgium in the 1860s. Unusually, when this shark died 15 million years ago, about 150 of its cartilaginous vertebrae became fossilised, providing a unique opportunity for Professor Shimada to study more than just its teeth.

By comparing the relationship of vertebral size and body length in modern great white sharks, palaeontologists can estimate the length of extinct sharks from the size of their vertebrae. The vertebrae in this megalodon specimen measure up to $15 \mathrm{~cm}$, indicating that this individual was about $9 \mathrm{~m}$ long.

Professor Shimada used a technique called computer tomography (CT) to peer inside the fossilised vertebrae, looking for hidden anatomical structures. "The CT images revealed that the vertebrae had 46 growth bands," he says. Much like the way annual growth rings form in trees, a shark's age can be determined by counting the growth rings in its vertebrae. "Therefore, this 9-metre-long megalodon died when it was 46 years old," explains Professor Shimada.

But that is not all that Professor Shimada discovered. "By back-calculating its body length when each growth band formed, my study suggests that the shark's size at birth was about two metres in length," he says. "This result implies that megalodon possibly gave birth to the largest babies in the shark world!"

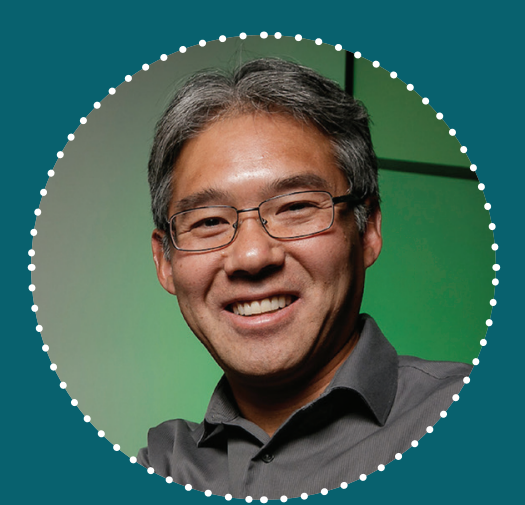

PROFESSOR KENSHU SHIMADA

Professor of Palaeobiology, DePaul University, USA

Research Associate, Sternberg Museum of Natural History, Fort Hays State University, USA

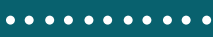

\section{FIELD OF RESEARCH}

Shark Palaeontology

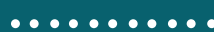

\section{RESEARGH PROJECT}

Investigating prehistoric sharks by studying modern sharks and fossils of extinct species

[.........

\section{FUNDER}

US National Science Foundation (Sedimentary Geology and Paleobiology Award to Kenshu Shimada, Award Number 1830858)

\section{HOW DID MEGALODON BABIES}

\section{GROW SO LARGE?}

As megalodons were already larger than a human by the time they were born, this suggests they were well-fed before birth. The most likely explanation for this is that the embryonic sharks fed on unhatched eggs of their siblings in the womb, a behaviour known as oophagy. While this might sound sinister, all modern-day lamniform sharks are oophagous, and the practice provides many advantages for the individuals which survive to birth.

"This egg-eating behaviour means that only a few pups will survive and develop," explains Professor Shimada, "but each can grow considerably large before it is born. New-born megalodons would have an advantage in the ocean as they would already be large predators at birth, so they would be less likely to get eaten by other predators."

\section{While Professor Shimada's research is}

painting a picture of the lives of the ferocious megalodon, there is still so much to discover about the ancient oceans. 


\section{. ABOUT PALAEONTOLOGY}

"The fossil record is a window into the history of life," says Professor Shimada. "It unequivocally shows the Earth's ecosystems have evolved over time." Palaeontologists study ancient life, from microscopic plankton to gigantic sea creatures, from the first trees to the last non-avian dinosaurs, and use their knowledge to investigate past ecosystems.

The fossil record shows that if ecosystems are disrupted, catastrophic changes can occur. Past mass extinction events have been linked to periods of global warming and global cooling, when Earth's climate changed too rapidly and dramatically for organisms to adapt. Understanding ancient ecosystems and their evolution is, therefore, crucial to predicting what may occur to modern ecosystems if current climate and environmental changes continue to occur.

Knowledge of ancient oceans can help modern marine conservation efforts. "Sharks are major carnivores that are vital for maintaining the balance of marine ecosystems," says Professor Shimada. "The extinction of prehistoric sharks, like megalodon, played an important role in shaping marine ecosystems as we know them today. Therefore, the extinction of modern sharks is predicted to have a profound impact on future ecosystems." For this reason, it is important to promote conservation of all organisms within all ecosystems.

To fully understand the ecosystems in which prehistoric sharks lived, Professor Shimada does not just study the sharks themselves. "If I want to understand the evolution of marine ecosystems over time, I need to know about other organisms that existed in the ecosystem as well," he says. "So, I also study other fossil vertebrates that co-occur with fossil sharks, such as bony fish, marine reptiles and sea birds." This allows him to build a more complete picture of what life was like in the ancient oceans.

\section{WHAT DOES PROFESSOR SHIMADA} FIND MOST REWARDING ABOUT HIS JOB?

"Studying fossil sharks is my hobby!" says Professor Shimada. "I am very fortunate to have a career that allows me to pursue my passion and share my interests with students,

\section{exPLORE A GAREF IN PALAEONTOLOGY}

- Most palaeontologists work as educators, researchers, or technicians at universities or in museums. You could work as a collections manager, exhibit designer or public outreach coordinator. You could be a fossil preparator, revealing the ancient creatures hidden within rocks, or a scientific artist, drawing or building 3D reconstructions of prehistoric organisms for museum exhibits, films or books. Or, you could become a science reporter to inform the public about discoveries palaeontologists make.

- "If you want to be a palaeontologist, you should take initiatives to be an active learner and proactively seek opportunities," says Professor Shimada. Contact local palaeontologists in museums or at universities to learn about their research programme and ask if they can offer you any palaeontology-based experiences.

- Palaeontologists study everything from dinosaur footprints to woolly mammoth tusks. Visit museums, read books and watch documentaries about fossils and natural history to discover which aspects of palaeontology most interest you.

- Go fossil hunting! Are there any geological sites near you where you could look for fossils? Remember to be a responsible palaeontologist. Check whether you need permission before collecting fossils, and do not remove fossils from protected areas.

colleagues and the public." Palaeontologists answer questions that have been unresolved for millions of years, and Professor Shimada enjoys discovering and sharing new knowledge about the natural world. "However, the most rewarding part of my job is when I witness a student's 'moment of discovery' by seeing their eyes suddenly light up from learning something new," he says.

WHAT ISSUES WILL FACE

THE NEXT GENERATION OF

\section{PALAEONTOLOGISTS?}

Fossils are priceless non-renewable resources which require careful protection and preservation. Unfortunately, many scientifically significant fossils are sold on the commercial market to private collectors, where they become lost from science and the public. There are also many cases of illegal fossil trading, and occasionally even human rights violations associated with the mining of fossils. "The next generation of palaeontologists must be mindful, global citizens, spreading the joy of palaeontology in a responsible way," says Professor Shimada.

\section{PATHWAY FROM sGHOOL TO PALAEONTOLOGY}

-At school, geology and biology are key subjects to study. Chemistry, physics, statistics and computer science are also useful for palaeontologists.

- As palaeontology requires skills and knowledge from both geology and biology, an undergraduate degree in either subject can lead you into the field. Professor

Shimada recommends taking biology classes in anatomy, ecology and evolution, and geology classes in sedimentary geology and field methods.

- With a degree in geology or biology, you can then specialise and study a master's degree in palaeontology. To become an academic researcher like Professor Shimada, you may also want to earn a $\mathrm{PhD}$ degree. 


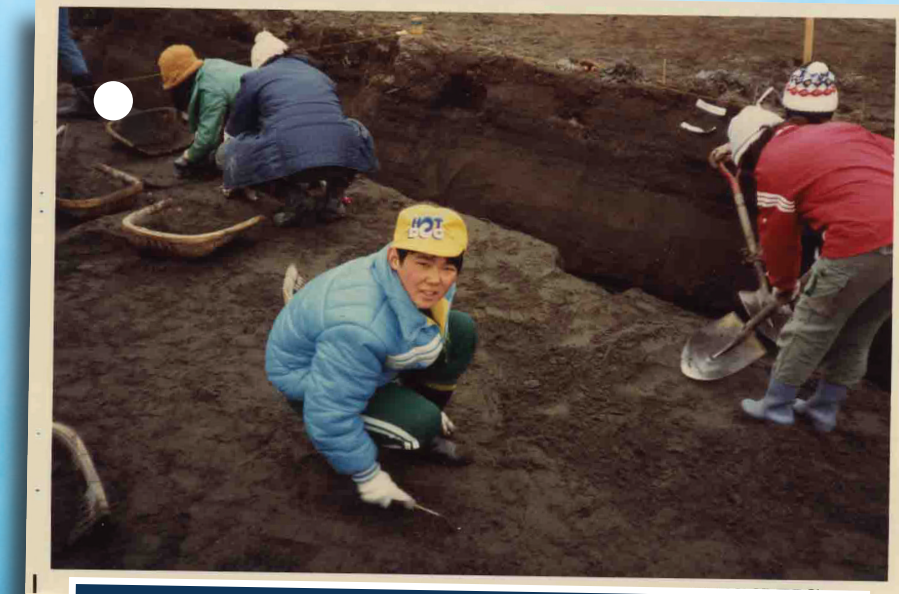

Professor Shimada involved with the Lake Nojiri Investigation Team's fossi excavation at age 12 .

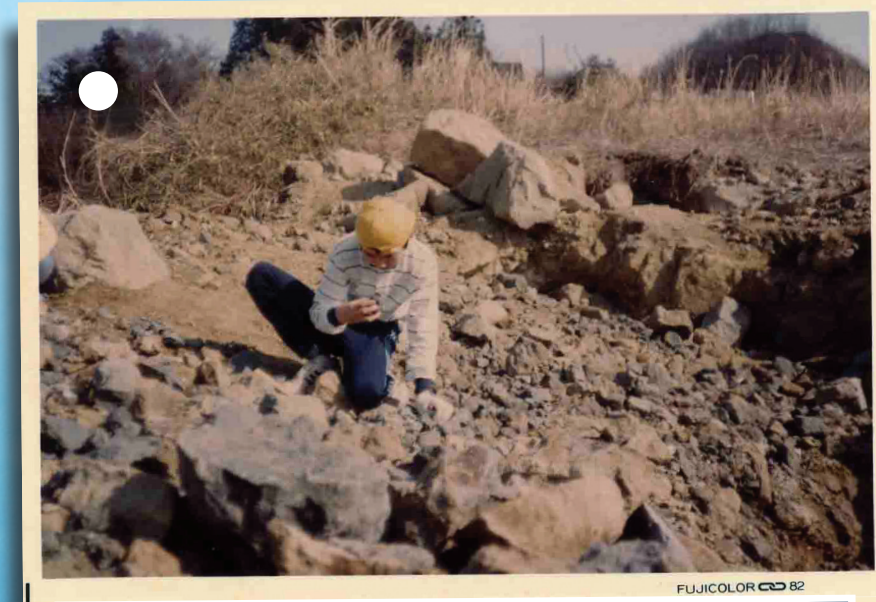

Professor Shimada at age 13 looking for fossils. This trip turned out to be the day he found his very first shark fossil (a megalodon tooth!) that changed his life forever.

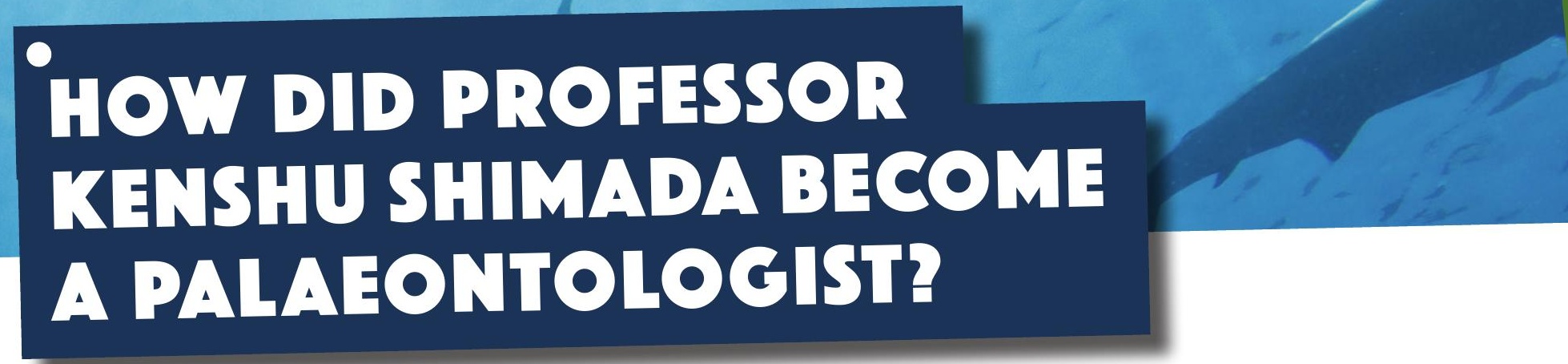

I developed a keen interest in fossils when I was 12 years old. I lived in Japan and

frequently visited libraries and bookstores to learn about how and where to collect fossils. I became an avid fossil hunter, spending most of my weekends and holidays looking for fossils. I joined the Lake Nojiri Investigation Team, an organisation that allowed amateur fossil enthusiasts like me to participate in major palaeontological excavations.

When I was 13 , I visited a fossil site featured in a geology guidebook, where I discovered a 5-cm-tall megalodon tooth. This incredible and unexpected discovery, combined with the impressive size and mesmerising beauty of the fossilized tooth, had a profound impact on my life. In fact, that was when I became interested in studying fossil sharks, and that discovery has led me to be the scientist am now.

Many high school teachers and local college professors mentored me through my teenage years, by encouraging and supporting my enthusiasm for fossils. My success as a professional palaeontologist today could not have happened without the kindness and attention they gave me when
I was a youngster. My mother also strongly encouraged me to pursue my passion.

I was fortunate to find my interest and passion early on in life. However, one challenge I faced as a consequence of this was struggling to balance my enthusiasm for palaeontology with my regular schoolwork. While I was a 'good' student, I was not academically strong. But my desire to become a palaeontologist drove me to study hard, and my efforts paid off when I was able to go abroad to attend college in the United States to receive formal training in palaeontology.

One highlight of my career was receiving a very competitive grant from the US National Science Foundation to investigate the biology of megalodon. It allowed me to address questions about the size, growth and reproductive strategies of megalodon. This research has also provided me with new opportunities to collaborate with a wide range of other scientists.

I look forward to unlocking more mysteries surrounding the megalodon and other extinct sharks. The fact that most prehistoric sharks are represented only by their teeth in the fossil record gives palaeontologists opportunities to ask many scientific questions. I like to take up nature's challenges.

Outside of my work, I enjoy fishing, including catch-and-release shark fishing. Although this is a hobby, it also feeds back into my research on ancient marine ecosystems by enabling me to observe and experience live modern organisms in their actual habitats.

\section{PROFFSSOR SHMADAS TOP TIPS}

01 Follow your passions.

02 Be proactive and search for opportunities.

03 Spend time outdoors in nature as much as you can.

04 Be imaginative and creative. Think 'outside the box' when you face a challenging problem. 